\title{
O processo de expatriação na estratégia organizacional
}

A interação entre as multinacionais, a matriz e as práticas de Gestão de Recursos Humanos (GRH) tem sido um desafio para as organizações, pois, embora os estudos na área de internacionalização de GRH com ênfase na expatriação e na estratégia organizacional tenha aumentado, estes não têm abordado fatores estratégicos fundamentais para a implementação da estratégia organizacional. Apesar de existirem modelos de internacionalização, poucos são os que consideram a expatriação com um processo importante na condução na internacionalização da empresa. A expatriação está relacionada com o negócio da empresa e não somente com a GRH. Dependendo dos objetivos da empresa, o conceito de expatriado pode ser entendido de diversas maneiras. Os diversos conceitos das missões internacionais se caracterizam em função do trabalho a ser desempenhado, da duração e da quantidade de viagens realizadas na missão. Essa diversidade surge como uma demanda para englobar um processo que vem tomando uma dimensão mais ampla em função da sua importância para as estratégias internacionais das empresas. Para tanto, esse estudo teórico busca abordar a expatriação mais do que uma prática de GRH, sendo, portanto, um processo ligado à estratégia internacional da empresa.

Palavras-chave: Expatriação; Gestão de Recursos Humanos Estratégico; Internacionalização; Repatriação.

\section{The expatriation process in organizational strategy}

The interaction between multinationals and Human Resource Management (HRM) practices have been a challenge to organizations. Despite the increase of studies in the area of internationalization of HRM which emphasize expatriation and organizational strategy, these have not addressed key strategic factors for the implementation of organizational strategy. From the various models of internationalization, only a few consider expatriation as an important process in driving the internationalization of the company. Expatriation is related to the business of the company and not just the HRM field. Depending on the objectives of the company, the concept of expatriation can be understood in different ways. The various concepts of international missions are characterized according to the work to be performed, the duration and the amount of travel undertaken in the mission. This diversity arises as a demand to encompass a process that has been taking a wider dimension according to their importance for international business strategies. For both, this theoretical study seeks to address the expatriation as a strategic process, and therefore more than one HRM practice, which is linked to international business strategy.

Keywords: Expatriation; Strategic Human Resources Management; Internationalization; Repatriation.

\section{Topic: Recursos Humanos}

Reviewed anonymously in the process of blind peer.

\section{Shalimar Gallon}

Universidade Federal do Rio Grande do Sul, Brasil

http://lattes.cnpq.br/0624744634005782

shalimargallon@gmail.com

Elaine Di Diego Antunes

Universidade Federal do Rio Grande do Sul, Brasil

http://lattes.cnpq.br/9333404937259230

elaine.antunes@ufrgs.br
Received: 05/10/2015

Approved: 14/01/2016
Referencing this:

GALLON, S.; ANTUNES, E. D.. O processo de expatriação na estratégia organizacional. Revista Brasileira de Administração Científica, v.7, n.1, p.43-60, 2016. DOI: http://doi.org/10.6008/SPC2179684X.2016.001.0004 


\section{INTRODUÇÃO}

A internacionalização, por vezes, se impõe como uma necessidade para a sobrevivência das empresas, requerendo uma gestão global que busque compreender e envolver as diversidades encontradas no novo ambiente, para que a empresa consiga ter destaque no mercado. A gestão global pode ser observada como uma prática que visa desenvolver estratégias, planejar e operacionalizar sistemas, trabalhando com pessoas do mundo inteiro em busca de vantagem competitiva (DERESKY, 2004).

Nesse contexto internacional, as empresas têm dificuldade de adaptação ao mercado, por estarem se envolvendo em um ambiente no qual, muitas vezes, há conflito cultural, dificuldade de adaptação dos empregados à cultura da empresa, falta de conhecimento sobre o mercado local, entre outros fatores. Em razão disso, as organizações demandam a liderança de executivos que se encontram na empresa matriz, numa tentativa de amenizar tais problemas nas empresas subsidiárias.

A estratégia de enviar os empregados da matriz para as subsidiárias em missão internacional tem sido corrente no meio empresarial. Essa estratégia denomina-se processo de expatriação, e ocorre quando um empregado assume um cargo pela empresa, em país estrangeiro, pelo período de um ou dois anos (DUTRA, 2002; CALIGIURI, 2000). Esse processo normalmente é implementado quando as empresas buscam desenvolvimento da liderança dos executivos, expansão de novos mercados, aquisição de conhecimento dos indivíduos, aumento na participação dos mercados de atuação e transferência de tecnologia.

É importante entender como o processo de expatriação influencia e é influenciado pelas estratégias de internacionalização da empresa. Os diversos níveis de internacionalização (internacional, multinacional, global e transnacional), bem como estruturas e orientações de gestão (etnocêntrica, regiocêntrica, policêntrica e geocêntrica) conduzem as estratégias das organizações, a fim de otimizar o papel de todas as áreas. Apesar de esses modelos, tanto de internacionalização como de orientação de GRH, trazerem contribuições para a Gestão Recursos Humanos Internacional Estratégica, abordam de forma ampla as relações entre as partes e não consideram a expatriação como um processo fundamental na estratégia de internacionalização. Esse processo é visto como uma prática de treinamento e desenvolvimento gerencial; no entanto, a expatriação auxilia no desenvolvimento da internacionalização da empresa.

Essas são algumas das lacunas que evidenciam a necessidade de melhor compreender as questões associadas à GRH dentro de um contexto global e avançar em seu conhecimento (SCHULER, 2000). Nesse sentido, esse estudo teórico propõe-se a analisar como a expatriação se relaciona com a estratégia de internacionalização das organizações, sendo essa considerada um processo fundamental. O foco do presente estudo é a importância da expatriação na internacionalização. Portanto, optou-se por não tratar de forma aprofundada a discussão das teorias de internacionalização, a qual, embora importante, não caracteriza a delimitação do tema deste estudo.

\section{DISCUSSÃO TEÓRICA}

\section{A expatriação como um processo na estratégia de internacionalização organizacional}


Em termos metodológicos, esse estudo configura-se como um ensaio teórico. Para construí-lo inicialmente foi feita uma busca nas publicações impressas, tais como Bohlander et al. (2003) e Ivancevich (2008). Também foram pesquisados artigos no site do Encontro Nacional da Associação de Pós-Graduação e Pesquisa em Administração (EnANPAD) até o ano de 2011. Com base nesse levantamento, buscou-se os artigos citados em suas referências; foram, pois, priorizados os artigos pioneiros e renomados na área de expatriação no meio empresarial, tais como Black e Gregersen (1999), Black et al. (1992), De Cieri et al. (1991), Lazarova e Caligiuri (2004), Mendenhall et al. (1987), Stroh (1995) e Tung (1988; 1987; 1998). A fim de atualizar a revisão da literatura, foi também realizado um levantamento nos periódicos da CAPES, no período de 2007 a 2012, visando identificar quais políticas e práticas de expatriação estão sendo utilizadas pelas empresas.

Para compreender a expatriação como um processo que oferece suporte para a estratégia de internacionalização organizacional busca-se: (i) caracterizar o papel da área de Gestão de Recursos Humanos Internacional (GRHI) nas estratégias organizacionais; (ii) conceituar e descrever o processo de expatriação; e (iii) analisar o processo de expatriação dentro da estratégia organizacional.

\section{O papel da gestão de recursos humanos internacional nas estratégias organizacionais}

O papel da Gestão de Recursos Humanos $(\mathrm{GRH})^{1}$ é o de se concentrar no alinhamento de suas estratégias e práticas à estratégia empresarial como um todo. Para que essa área se torne um parceiro estratégico é necessário que esteja presente no processo de definição da estratégia empresarial, promova questionamentos para transformar a estratégia em ações e promova práticas de GRH que estejam adequadas à estratégia empresarial (ULRICH, 2000). Além disso, a importância de se ter um modelo integrado que busque articular os processos de GRH entre si é fundamental, a fim de mostrar a amplitude dessa área dentro das estratégias organizacionais (DUTRA, 2002)

Para que a GRH contribua para o negócio da organização, é necessário que suas políticas e práticas tenham origem nas demandas estratégicas e não apenas em interesses circunstanciais (DE RÉ; DE RÉ, 2011). O investimento realizado em GRH deve estar ligado coerentemente com a estratégia, pois essa é a única forma de se ter um resultado positivo e contínuo. Quando as estratégias forem alteradas, a configuração de GRH também será alterada, mantendo assim, uma estrutura intimamente conectada (TANURE et al., 2007).

Para Richey e Wally (1998), a preocupação acadêmica sobre a Gestão de Recursos Humanos evoluiu a partir da percepção de que as estratégias de Recursos Humanos podem ser cruciais para a efetiva realização de estratégias empresariais. Ressaltam, entretanto, que as áreas de planejamento estratégico e de GRH também se desenvolveram, mas nem sempre em conjunto. Houve, no entanto, crescente reconhecimento de que as estratégias são, muitas vezes, se não principalmente, emergentes e que a gestão estratégica deve se basear no desenvolvimento de organizações que podem promulgar ambientes, ao invés de reagir a eles

\footnotetext{
${ }^{1}$ Esse estudo adota a nomenclatura de Gestão de Recursos Humanos (GRH), visto que o estudo está baseado na literatura anglo-saxônica, a qual denomina essa área como Human Resource Management (Gestão de Recursos Humanos), embora, no Brasil, a denominação corrente da área seja Gestão de Pessoas (GP).
} 
por meio de planejamento formal e de programas de implementação (RICHEY; WALLY, 1998), conforme exposto por De Ré e De Ré (2011).

Boxall e Purcell (2008) analisam que a estratégia é estruturada no comportamento dos negócios, o qual é composto de um conjunto de estratégias que abrangem as várias áreas funcionais do negócio, como marketing, produção, finanças e recursos humanos. Os autores explicam que a palavra estratégia implica algo que tem consequência para o futuro da empresa e destacam que o problema de uma estratégia é sua viabilidade. Para ser viável, uma empresa precisa de um conjunto adequado de metas e um conjunto relevante de recursos humanos e não humanos, uma configuração ou sistema de fins e meios compatíveis com a sobrevivência das indústrias e das sociedades em que atua. Isto obviamente significa que, sem certos tipos de capacidade humana, as empresas simplesmente não são viáveis.

Isso possibilita entender que estratégia eficaz da Gestão de Recursos Humanos é uma condição necessária, embora não suficiente, da viabilidade da empresa. Logo, gestão estratégica é o processo usado, na empresa, para desenvolver os objetivos e recursos críticos, tendo correlação com a Gestão de Recursos Humanos, pois se trata não só de tomar algumas decisões importantes sobre a GRH (recrutamento, desenvolvimento e promoção dos gestores-chave), mas também de envolver toda organização, desde equipes operacionais até a gerência (BOXALL; PURCELL, 2008).

A integração entre GRH e a estratégia de negócios é um processo complexo e dependente da interação dos recursos das diferentes partes interessadas, como exposto por Boxall e Purcell (2008). A evolução de abordagem para estratégia tem como argumento que as tentativas conscientes para integrar a estratégia e a política de Gestão de Recursos Humanos são um benefício para as empresas e, na pior, uma irrelevância, salientando-se que as organizações nada têm a perder ao levarem em consideração a GRH, pois sempre há o que agregar.

A intenção estratégica e o planejamento organizacional são processos críticos na determinação das bases de um processo de gestão internacional. Mccall e Hollenbeck (2003) analisam que as empresas devem se questionar sobre qual trabalho precisa ser executado, pois são as respostas a esta questão que orientarão o desenvolvimento de qualquer organização. A estratégia empresarial e a estrutura de uma empresa afetam diretamente o número e o tipo de cargos internacionais, o número de executivos, o conhecimento de quais habilidades são necessárias e de quais as experiências disponíveis para ensinar o que eles precisam saber. Por exemplo, diretores em um país versus diretores de empresas globais versus diretores de uma função versus diretores de alianças, quais tipos de atribuições estão disponíveis para o desenvolvimento, onde elas se localizam e quais culturas precisam ser compreendidas são levantamentos necessários na compreensão da internacionalização (MCCALL; HOLLENBECK, 2003).

Uma empresa que não tem definida ou está confusa quanto à sua estratégia global terá dificuldade em planejar uma estratégia coerente para a GRH. Mesmo aquelas que estão certas quanto à sua estratégia enfrentam diversos desafios, em parte por causa de problemas inerentes à integração ao redor do mundo e, em parte, porque a estratégia e a estrutura precisam permanecer flexíveis e mudar conforme as necessidades empresariais (MCCALL; HOLLENBECK, 2003). 
O desafio das multinacionais para conduzir seus negócios no exterior é influenciado pela opção da estratégia de negócios a ser usada e pela definição de qual estrutura será mais eficiente para sua operacionalização (NOGUEIRA et al., 2012). Isso implica no nível de maturidade internacional que organização tem - multinacional, internacional, globalizada ou transnacional ${ }^{2}$ (BOHLANDER et al., 2003; IVANCEVICH, 2008; VANCE; PAIK, 2006) - tanto na orientação de GRH: geocêntrica, etnocêntrica ou policêntrica3 (IVANCEVICH, 2008; VANCE; PAIK, 2006). Cada estratégia de negócios, bem como cada estrutura, determina as maneiras de pensar e agir dos executivos e, consequentemente, as políticas e práticas no gerenciamento global de GRH (NOGUEIRA et al., 2012). A estratégia organizacional além de definir o desenho organizacional, também define o perfil das pessoas a serem contratadas (DE RÉ; DE RÉ, $2011)^{4}$.

Para as empresas que ainda veem sua estrutura de forma doméstica, Mccall e Hollenbeck (2003) ressaltam que todo negócio é, em certa medida, global. Esse pensamento é importante para que a organização comece a se ver, não só em um contexto global, mas também de maneira global, para que possa, antecipadamente, desenvolver estratégias e estruturas em relação ao contexto internacional (MCCALL; HOLLENBECK, 2003).

O conhecimento das condições em uma variedade de países e o conhecimento de como gerir, tanto dentro quanto entre eles, é a essência da Gestão de Recursos Humanos Internacional (GRHI). As complexidades de operar em diferentes países, empregando diferentes categorias nacionais de trabalhadores é uma variável-chave que diferencia a GRH nacional da internacional. Diferenciar essas duas áreas é a ligação da GRH com questões de nível estratégico das empresas multinacionais (SCHULER, 2000).

Em termos de GRHI, Schuler (2000) analisa que há necessidade de uma GRHI Estratégica dentro do GRH. A GRHI estratégica refere-se às questões de Gestão de Recursos Humanos, funções, políticas e práticas que resultam das atividades estratégicas das empresas multinacionais, impactando as preocupações internacionais e os objetivos dessas empresas (SCHULER et al., 1993). Embora esta definição seja semelhante com a GRH doméstica, ela é ampliada para o âmbito internacional na expectativa de que se torne uma vantagem competitiva no contexto global, bem como nos multimercados domésticos, visto que a interação entre os diversos GRH é relevante para a implementação da estratégia global.

\footnotetext{
${ }^{2}$ Esses tipos de organizações diferem quanto ao grau em que as atividades internacionais são separadas, para atender às regiões locais, e integradas, para atingir com eficiência global. Entende-se por empresa internacional aquela que usa as capacidades que possui para penetrar nos mercados externos. A empresa multinacional (ou multidoméstica) é uma forma mais complexa que, em geral, tem unidades plenamente autônomas operando em vários países. A empresa global tende a tratar o mercado mundial como um todo unificado e tentam combinar as atividades em cada país para maximizar a eficiência em escala global (BOHLANDER et al., 2003). A empresa transnacional atende as exigências e necessidades locais de uma multinacional enquanto busca a eficiência de uma empresa global, na busca de um equilíbrio entre global/local (MURITIBA; ALBURQUERQUE, 2009).

${ }^{3}$ Por exemplo: uma empresa multinacional, principalmente nos estágios iniciais de se tornar empresa internacional, provavelmente adotará uma perspectiva relativamente etnocêntrica, tentando adotar as políticas de GRH do próprio país com o mínimo de adaptações. A organização multinacional nova, etnocêntrica, geralmente acredita que todos os empregados importantes devem ser empregados da matriz, pois acha que sua maneira de fazer as coisas é superior em comparação com as das outras culturas (BOHLANDER et al., 2003).

${ }^{4}$ A organização que possui uma orientação etnocêntrica tem como pressuposto de que as principais funções de tomada de decisão estão centralizadas na sede corporativa. A orientação policêntrica tem uma estratégia multidoméstica e utilizada pessoas do país anfitrião para gerir a organização estrangeira. A orientação geocêntrica pressupõe que os empregados mais qualificados ocupem os cargos gerenciais dentro das corporações internacionais, independentemente da nacionalidade (VANCE; PAIK, 2006).
} 
As principais razões para o desenvolvimento da Gestão de Recursos Humanos Internacional Estratégica inclui perceber que a GRH, em qualquer nível, é importante para a implementação da estratégia; que os principais componentes estratégicos da subsidiária têm grande influência em questões da gestão internacional, funções, políticas e práticas da subsidiária; que muitas das características do GRHI podem influenciar a obtenção das metas das empresas coligadas; que existe grande variedade de fatores que tornam a relação entre as subsidiárias e o GRHI complexos, transformando o estudo dos GRHI estratégico em desafio (SCHULER et al., 1993).

Há autores como Bohlander et al. (2003) que dão um enfoque mais limitado para essa área, observando que a GRI atribui maior ênfase às funções e atividades como transferência, orientação e serviços de tradução, para facilitar a adaptação dos empregados a um ambiente novo e diferente, fora de seu país. Esse conceito direciona somente para a expatriação, sendo, porém, essa área mais ampla. Para Taylor et al. (1996 apud QUINTANILLA, 2002), essa área pode ser entendida como todas as atividades que influenciam a conduta dos indivíduos e seus esforços por estabelecer e desenvolver uma estratégia internacional.

Quintanilla (2002) observa tal lacuna, ao ressaltar que se deve ter uma visão mais ampla dessa área, para que se possa entender as contribuições e os resultados de todos os tipos de empregados e não somente dos expatriados, a fim de ter melhor noção do direcionamento da empresa e, assim, traçar estratégias internacionais mais eficientes. De fato, além de o conhecimento dos expatriados, os empregados domésticos também têm um papel significativo na articulação das interfaces local e global.

Por todo exposto, é evidente a necessidade de entender o papel estratégico e promover espaço para a GRH dentro das organizações. Essa área é mais do que o gerenciamento de seus recursos humanos, pois busca desenvolver seus empregados, por meio de suas práticas, a fim de alcançar os objetivos estratégicos da organização. Além disso, se mostra presente na articulação entre o global e o local, possibilitando a valorização e desenvolvimento de todos os aspectos das atividades globais e internacionais.

Uma empresa pode decidir mudar sua orientação estratégica de doméstica para global no espaço de alguns anos, porém o desenvolvimento das competências necessárias de GRH não pode ser feito tão rapidamente. Leva tempo para que uma equipe ou um grupo inteiro de GRH aumentar suas capacidades de gestão global e suas competências. Este desenvolvimento precisa começar antes da implementação real de mudança estratégica da empresa. A expatriação é um processo que auxilia nessa interface, embora não receba tal reconhecimento.

\subsection{Entendendo o processo de expatriação}

Por longos períodos, o termo 'internacional' foi suficiente para denominar as operações fora do país de origem, sendo o executivo internacional alguém que vivia e trabalhava 'no estrangeiro' (MCCALL; HOLLENBECK, 2003). Com o incremento das relações nos negócios, novos conceitos surgiram, tal como o de expatriação. Esse conceito, normalmente, varia em relação ao tempo que o empregado ficará fora do país de origem. De acordo com Dutra (2002), expatriado é o empregado que "terá que atuar por um período ou 
de forma definitiva em um país diferente daquele no qual foi contratado para trabalhar". Caligiuri (2000) complementa essa definição, ao observar que os expatriados são os empregados enviados por uma empresa para viver e trabalhar em outro país, por um período que pode variar de dois a mais anos. Ele também pode ser definido como um executivo que não é cidadão do país no qual está designado para trabalhar (SHEPHARD, 1996).

Nunes et al. (2008) analisam que a expatriação consiste no deslocamento de um profissional a um destino internacional, com determinação de elementos como função, período, condições financeiras, localização. Apesar de o conceito ser similar aos dos autores anteriores, esses estudiosos dão uma valiosa contribuição para a expatriação, pois acreditam que a estratégia da empresa define o objetivo e o modelo de expatriação e, consequentemente, o perfil do expatriado. A expatriação pode, portanto, ser entendida como uma estratégia de GRH que visa tanto desenvolver internacionalmente a organização como as competências do executivo global, nos empregados.

Zwielewski (2009) amplia o conceito e analisa a expatriação como o ato de alterar rotinas, costumes, valores pessoais, construir uma nova rede de relacionamentos, tanto para a pessoa que está sendo expatriada como para sua família, e proporcionar-Ihes uma nova infraestrutura para que, ao enfrentarem os desafios, estejam bem emocionalmente. Essa autora mostra que a expatriação também está conectada a fatores pessoais e não somente à saída do empregado do país de origem.

Freitas e Dantas (2011) compartilham desse último conceito e o complementam, ao relatarem que a expatriação está relacionada a um sujeito que desenvolve a capacidade de se adaptar a culturas diferentes e de lidar com o desconhecido. As pressões psíquicas têm menor impacto em sua vida e ele consegue responder às exigências do novo quotidiano sem grandes desconfortos. Esses aspectos interligam-se à questão do perfil e da identidade do sujeito. Referindo-se a esses dois aspectos, as autoras relatam que o expatriado é aquele com quem o aprendizado instrumental do mundo do trabalho contribui para que ele saiba lidar com mudanças frequentes, sem maiores alterações de sua identidade, ou seja, ele é um sujeito adaptável a novos ambientes.

Observando essas definições, entende-se que o conceito de expatriação também pode variar de acordo com a legislação de cada país. No caso do Brasil, desde o início de julho de 2009, todos os trabalhadores brasileiros que prestam serviço no exterior passaram a ter sua relação de emprego regida pelas disposições contidas na Lei no 7.064, de 06 de dezembro de 1982, anteriormente aplicada apenas aos empregados de empresas prestadoras de serviços de engenharia, consultoria, projetos e obras, montagens, gerenciamento e congêneres (BRASIL, 2012). Hoje, a Lei no 11.962, publicada no Diário Oficial da União, em 06 de julho de 2009, retirou a especificação do segmento no qual a empresa atua, deixando expresso que todos os trabalhadores contratados no Brasil ou transferidos por seus empregadores para prestar serviço no exterior estão submetidos ao mesmo regime (BRASIL, 2012). Ainda de acordo com a Lei no 7.064/82 (artigo 1ㅇ), ressalta-se que fica excluído do regime o empregado designado para prestar serviços de natureza transitória, por um período menor a 90 dias (BRASIL, 2012). Devido a essa delimitação, os empregados só se 
tornam expatriados, perante a lei, e isso implica o recebimento de benefícios e remuneração como expatriado, após 90 dias no país estrangeiro.

Tal qual o conceito de expatriação, as configurações de expatriados variam de acordo com as concepções dos autores. Assim como existem os expatriados, também há os repatriados que são aquelas pessoas que saíram do país de origem, a convite da empresa, para trabalhar em uma subsidiária, e estão retornando para seu país de origem. Ou seja, repatriados são os expatriados de retorno à empresa matriz. Alguns autores fazem diferença entre enviar um empregado da subsidiária para matriz ou o inverso. Assim, surgem os impatriados: pessoas das subsidiárias que trabalham em missões temporárias na matriz da empresa (HARVEY et al., 2000). Esses vêm com o intuito de aprender a cultura da empresa matriz e levá-la para a subsidiária.

Há ainda outras configurações de expatriados. O conceito de flexpatriado refere-se aos empregados que circulam entre países, em estadas de curta duração e não se fazem acompanhar pela família para poderem responder às necessidades de flexibilidade das empresas (REGO; CUNHA, 2009). O conceito de cidadãos do mundo está próximo à definição de flexpatriados, por serem pessoas que transitam por diversos países, se adaptam facilmente a outras culturas e já perderam a identidade de cidadão de um único país (BOHLANDER et al., 2003). Tanure et al. (2007) entendem que esse empregado é um executivo transnacional, o qual conhece e aprecia culturas variadas e tem, por competência, transitar rotineiramente por diversas culturas e países com facilidade, durante sua carreira profissional.

Ressalta-se que uma das tendências na carreira profissional é a carreira 'sem fronteiras', a qual supõe que os indivíduos vão se deslocar de uma empresa para outra, a fim de buscarem as melhores oportunidades, visando a seu próprio desenvolvimento profissional (TUNG, 1998). Essa perspectiva vai ao encontro dos conceitos de 'cidadão de mundo' e de executivo transnacional, que sinalizam o aumento desse tipo de expatriado.

Harvey e Novicevic (2006) discutem a patriação, a qual significa o retorno do expatriado depois de uma sequência de múltiplas realocações em uma empresa. Esse conceito é utilizado para o empregado da matriz que passa por diversas subsidiárias, por longos períodos, para que, ao final, possa retornar para a matriz e assumir um cargo executivo dentro da empresa. Essa técnica é conhecida como job rotation, porém de amplitude global e caráter estratégico, com a finalidade de possibilitar a compreensão de todas as operações internacionais. $O$ patriado tem por objetivo aprender as peculiaridades de cada subsidiária, a fim de obter vasto conhecimento sobre o mercado externo e trazê-lo para a matriz. A patriação é quase que o término de uma carreira de expatriado ou o auge do desenvolvimento de liderança global de um empregado.

A maioria dos estudos sobre expatriação (LIMA; BRAGA, 2010; TANURE et al., 2007; LAZAROVA; CALIGIURI, 2004; MENDENHALL et al., 2003; QUINTANILLA, 2002), não deixa claro a direção da expatriação (se é da matriz para subsidiária ou vice-versa), visto que as subsidiárias também demandam expatriações com a mesma importância. Como a subsidiária faz parte das estratégias globais, é válido que suas expatriações também façam parte de tal planejamento, embora esse tipo de expatriação não seja o foco das 
pesquisas sobre o tema. Assim, nesse estudo, o conceito de expatriação refere-se às missões da matriz para a subsidiária e no sentido contrário recebe o nome de impatriação.

Dentro dessas diferentes configurações de expatriação, Schuler et al. (2002) destacam um fator interessante ao planejamento da expatriação. Para a atribuição do expatriado, em contraste com a atribuição doméstica, a empresa precisa avaliar as dimensões de desempenho não especificamente ligadas ao trabalho, tais como qualidades interpessoais e interculturais; sensibilidade às normas estrangeiras, leis e costumes; adaptabilidade às condições incertas e imprevisíveis; integração ao local de acolhimento com as unidades da empresa.

A importância desses fatores varia de acordo com a configuração de expatriado que é enviado e como ele está posicionado na estratégia organizacional. Dependendo dos objetivos da empresa, o expatriado pode assumir diferentes configurações. Os diversos conceitos das missões internacionais caracterizam-se também em função do trabalho a ser desempenhado, a duração e a quantidade de viagens realizadas na missão. Os conceitos surgem como uma demanda para englobar um amplo processo que vem tomando maior dimensão, em função de sua importância dentro das estratégias internacionais das empresas, como observa McCall e Hollenbeck (2003):

responder às mudanças do ambiente internacional raras vezes resulta em estratégias lógicas implementadas de modo ordenado. Por exemplo, esforços de expansão internacional ao acaso (que, em retrospectiva, melhor se descrevem como ingênuos) amiúde começam com: -"quem podemos mandar para a China (ou qualquer outro lugar)?" Se o negócio fracassa, a falha é interpretada como sendo uma deficiência da pessoa enviada para liderar o empreendimento, em vez de ser vista como inerente ao empreendimento um tentativa de alto risco, mal preparada, de aumentar o negócio. Assim, não surpreende que as organizações internacionais percam líderes talentosos detentores de experiências inestimáveis.

Assim, é possível relacionar que dependendo do estágio de internacionalização e da estratégia da empresa, a organização passa a ter mais autonomia e maior diversidade de empregados. As estratégias de internacionalização têm impacto na configuração do empregado internacional (expatriado, impatriado, flexpatriado, patriado, repatriado, empregado global, cidadão do mundo e transnacional), de acordo com os objetivos da organização e nível de internacionalização da empresa. Isso porque conforme a organização se desenvolve internacionalmente, há uma demanda por diferentes configurações de expatriados. Inicialmente, a necessidade da empresa é de levar o conhecimento, por isso há uma orientação mais etnocêntrica, concentrando seus objetivos nas informações que os expatriados devem levar para as subsidiárias. Porém, quando a empresa alcança um nível global ou de transnacionalidade, exige-se que os empregados expatriados também retornem o conhecimento aprendido, denominando-o de repatriado. Ou ainda que ele circule por diversas unidades, com objetivo de ampliar o conhecimento do mercado global, tornando-se, assim, um cidadão do mundo, empregado global ou transnacional. Ao retornar à empresa matriz, ele recebe o nome de patriado. Quando a empresa opta por fazer o processo inverso, ou seja, expatriações da subsidiária para a matriz, os empregados são chamados de impatriados.

As configurações de expatriados variam de acordo com o objetivo e nível da internacionalização, os quais influenciam a orientação da GRH. Embora possa parecer uma relação facilmente estabelecida, a 
literatura atual sobre expatriação, internacionalização, GRH e estratégia não a aborda sob este contexto. Exemplo disso é o estudo de Vance e Paik (2006) que relaciona a orientação da GRH e a expatriação, entretanto não aprofunda o conhecimento dos diferentes configurações de expatriados, relacionando, somente, a presença de expatriados de acordo com o nível de internacionalização da empresa.

Através desses conceitos, é possível ver que a expatriação é, antes de tudo, uma decisão estratégica e um processo organizacional. Para o sucesso da expatriação é necessário, também, que as políticas e práticas estejam alinhadas às estratégias da empresa (TANURE et al., 2007), pois a expatriação está relacionada com o negócio da empresa e não somente com a área de Gestão de Recursos Humanos.

O estudo de Lima e Braga (2010) relata o levantamento de políticas e práticas de GRH utilizadas pelas empresas no Brasil, para garantir o sucesso do processo de repatriação e retenção dos repatriados. É revelado que as ações das empresas no processo de repatriação não são ações estratégicas e estão relacionadas ao suporte operacional ao repatriado. As políticas e práticas que poderiam solucionar ou minimizar os principais problemas que os repatriados enfrentam não são adotadas. Parece não haver disposição suficiente para se elaborarem políticas e práticas efetivas para o retorno e a retenção desses executivos.

Os resultados da pesquisa mostram que as principais políticas e práticas de recursos humanos para a repatriação são: manter o executivo informado sobre as mudanças que ocorrem na organização, durante a expatriação; pagamentos de viagens ao país de origem durante a expatriação; verba para realização da mudança; apoio durante o processo de expatriação; recolocação do executivo no mercado de trabalho, se não houver um posto apropriado no retorno. Algumas dessas políticas e práticas são adotadas apenas parcialmente, por exemplo, a comunicação evidencia-se deficiente na maioria das empresas.

Os dados mostram que as empresas pesquisadas justificam a falta de políticas para a repatriação, pois estão focadas em enviar executivos para o exterior e não em repatriar, ou por que o número de repatriados é muito baixo, ou por que os brasileiros não têm dificuldades de adaptação nem na expatriação, nem no retorno ao Brasil. Isso reflete uma 'miopia' da área de Recursos Humanos e dos gestores em geral, ao não saberem identificar o que a empresa perde, em termos de conhecimentos e competências, quando perde um executivo com experiência internacional.

As empresas ainda têm dificuldades em gerenciar a expatriação, principalmente pela informalidade de suas práticas. Elas acreditam que os aspectos financeiros compensam os incômodos de uma expatriação, entretanto os executivos expatriados não percebem dessa maneira. As expatriações englobam as exigências do mercado de trabalho atual e tendem a gerar, nos executivos, experiências que afetam suas expectativas de evolução pessoal e profissional; de representações sociais; de avaliação de suas próprias competências (HOMEM; DELLAGNELO, 2006). Esse é um dos motivos pelos quais os expatriados passam a valorizar mais sua experiência internacional e percebem que os aspectos financeiros não são tão importantes frente ao aprendizado adquirido. Isso acaba refletindo na valorização da carreira que está relacionada aos altos índices de desligamento de expatriados da empresa. 
Para entender o panorama da expatriação, Bianchi (2011) realizou, em 11 periódicos, um levantamento pertinente à temática de Gestão Internacional de Recursos Humanos, a fim de analisar o tema repatriação, por meio de uma revisão bibliográfica sobre ele. Ao total foram analisados 29 artigos, no período de 2000-2010. A autora observou que as pesquisas reforçam práticas e papéis de forma universalista, entretanto agregam a perspectiva da diferença entre tamanho e momento da empresa. Foi levantada também a importância das organizações em ter melhor atuação para todo o processo, enfatizando a valorização e a agregação do conhecimento do expatriado.

Nessa mesma pesquisa, a autora critica que, na maioria dos casos, as proposições teóricas desses trabalhos não são testadas e, por isso, não se consegue entender as demandas individuais. Apesar disso, os estudos com foco no indivíduo evidenciam os processos de mudança individuais e a validação das práticas organizacionais (BIANCHI, 2011). O levantamento mostra que há poucos estudos realizados, na América Latina, sobre a área de expatriação, não havendo estudos que busquem criar uma teoria. Sobretudo no Brasil, busca-se, nas teorias internacionais, a base teórica para as pesquisas realizadas. Consequentemente, não há a devida compreensão do contexto, visto que a realidade das empresas internacionais não é convergente com aquela na qual as empresas brasileiras estão inseridas.

A expatriação envolve diversas práticas mostrando-se, assim, um processo complexo com muitas possibilidades, mas também com grandes desafios pela frente. Os executivos desempenham diferentes tipos de trabalho global, variando conforme o negócio, as estratégias e também a cultura empresarial. Para isso, é necessário entender como o processo de expatriação está ligado aos negócios da organização ou pode auxiliá-los.

\subsection{O processo de expatriação na estratégia organizacional}

A expatriação é um processo que demanda estruturação, uma vez que envolve procedimentos, estratégias e pessoas. Ele compreende práticas como recrutamento; treinamento técnico e cultural; preparação e adaptação da família; fornecimento de documentos a todos os envolvidos, bem como suporte psicológico. Para tanto, essas práticas envolvem diferentes momentos do processo: tanto a ida, a viagem e o retorno do expatriado. Por isso, é importante entender que a expatriação não constitui apenas o deslocamento de um empregado para outro país. Ele é um processo amplo que engloba três momentos, os quais devem estar estruturados para que a expatriação seja bem sucedida. Essas três etapas são: (1) a preparação para a missão, (2) a missão em si e, (3) a volta da missão (repatriação).

Enfatiza-se a necessidade de entender a expatriação como processo 5 e não somente como prática. O foco no processo busca salientar que a expatriação não é uma prática estanque; é mais que isso. As fases da expatriação complementam-se; interagem entre si; fazem parte de algo maior dentro da organização, não

\footnotetext{
${ }^{5}$ Processo pode ser entendido como "uma metodologia que serve como ponto de união para uma série de atividades, de maneira a agregar valor" (TANURE et al., 2007) ou também ser analisado como as "interações entre partes com um objetivo e dentro de parâmetros previamente definidos" (DUTRA, 2002).
} 
sendo consideradas somente mais uma prática de GRH. A repatriação (última fase) serve, portanto, como base para as estratégias organizacionais e também para as futuras expatriações, pois nela centram-se os resultados da experiência internacional.

Nas estratégias internacionais da empresa, Schuler (2000) ressalta a necessidade de ser sensível às condições locais, pois há várias preocupações estratégicas relevantes para a GRHI, tais como a preocupação de ser global e a transferência de aprendizagem e, portanto, simultaneamente, ser multi-doméstica. Nesse sentido, o autor levanta alguns questionamentos em relação a como, através de políticas e práticas de GRH, as empresas multinacionais podem vincular as unidades dispersas globalmente e a como as empresas multinacionais facilitam uma resposta multi-doméstica que esteja, simultaneamente, de acordo com a necessidade de coordenação global e de transferência de aprendizagem e inovação em todas as unidades.

Essas perguntas trazem desafios inerentes à GRH e às estratégias globais das empresas. A expatriação dentro das estratégias pode auxiliar na transferência do conhecimento e também na interlocução das práticas. O foco recai sobre a repatriação que é o término da experiência internacional, mas ao mesmo tempo, também é o recomeço para traçar novas estratégias por meio do conhecimento obtido. Em cima do feedback da repatriação, desde o dos gestores da subsidiária até o do próprio repatriado, novas soluções e problemas poderão ser encontrados.

Entretanto, as organizações não percebem o rico conhecimento que a repatriação traz, pois, muitas vezes, o foco da expatriação é levar o conhecimento e, consequentemente, a repatriação seria o fim de um ciclo, sem maiores contribuições. Para uma empresa ser global, um dos desafios que as organizações enfrentam é a adaptação de suas práticas de Recursos Humanos ao novo conjunto de culturas, no qual a organização está operando, e a criação de formas de operação que sejam, ao mesmo tempo, confortáveis para a organização e apropriadas para aquelas culturas e para os indivíduos (HOMEM; DELLAGNELO, 2006; QUINTANILLA et al., 2008). O conhecimento trazido por uma repatriação auxilia tanto nas estratégias das organizações, pelo conhecimento do mercado, como na implementação de políticas e práticas de GRH global, ajudando a empresa a se tornar global.

A interação entre as multinacionais, a matriz e os países de acolhimento e as práticas de Gestão de Recursos Humanos têm sido um desafio para as organizações. Quintanilla et al. (2008) realizaram uma pesquisa com o intuito de entender a difusão de políticas e práticas de GRH por multinacionais com sede nos Estados Unidos para as suas subsidiárias na Espanha. A pesquisa relata o efeito 'país de origem', referente ao fato de as multinacionais estarem imersas em pressupostos, práticas e instituições do sistema nacional de negócios do qual surgiram. Isso pode estar relacionado ao isomorfismo sofrido pelas multinacionais, nos países de acolhimento.

O estudo apontou que, em geral, as multinacionais têm tendência a continuarem com as operações de forma centralizada e com a gestão de processos, políticas e sistemas formais e padronizados. No entanto, mostrou também que a influência crítica exercida pela gestão e pelos recursos internos das subsidiárias vai moldando o desenvolvimento dos sistemas de GRH dessas filiais (QUINTANILLA et al., 2008). Assim, a pesquisa revela que a área de GRH das subsidiárias concentra-se, principalmente, sobre a implementação e 
a adaptação de estratégias obrigatórias e políticas corporativas para as características legais e culturais do sistema de negócios espanhol. Nesse sentido, os autores relatam a prevalência de 'políticas corporativas' nas subsidiárias espanholas, o que manifesta o alto grau de universalidade de políticas e práticas.

A empresa, ao invés de buscar conciliar a diversidade para criar uma corporação global, impõe o planejamento único e o distribui entre as subsidiárias. Por isso, muitas empresas não conseguem ter suas estratégias globais bem-sucedidas, pois suas políticas e práticas são impositivas e não globalmente construídas. Igualmente, por esse motivo, as áreas de GRH das subsidiárias não conseguem espaço dentro da estratégia global, pois estão ocupadas em implementar práticas advindas da matriz, ao invés de construílas.

Enquanto o sucesso da implementação de políticas corporativas de GRH pode ser atribuído à maleabilidade do sistema empresarial espanhol e à legitimidade dada às práticas de GRH originárias dos EUA, Quintanilla et al. (2008) chamam a atenção para o papel dos gestores nas subsidiárias espanholas, que também têm significativo papel nesse processo. Cabe, então, tanto aos gestores dessas empresas como os expatriados sinalizarem as peculiaridades dos países e levarem informações para a matriz, para que a empresa possa chegar a uma estrutura global.

Outro estudo que examinou os determinantes da composição de pessoal de subsidiárias estrangeiras, adotando a teoria institucional como fundamento teórico é o de Ando (2011). O estudo contribui para a literatura da área de GRH, mostrando que as multinacionais têm dificuldade em mudar suas rotinas estabelecidas. Os resultados sugerem que o efeito da pressão institucional diminui a possibilidade de as multinacionais acumularem experiência internacional. Entretanto, a experiência internacional das multinacionais tem menos tendência a apresentar comportamento mimético, pois divergem do comportamento de outras empresas estrangeiras na mesma categoria. $\mathrm{O}$ autor ressalta que seria interessante investigar as pressões institucionais internas e externas, para avançar na compreensão da área de GRH nas subsidiárias.

Em relação à comunicação entre a matriz e a subsidiária e as políticas de internacionalização, os estudos de Becker-Ritterspach e Dörrenbächer (2011) e Dörrenbächer e Geppert (2009) ressaltam a importância da matriz projetar tanto um plano como oportunidades de carreira para os gerentes, a fim de influenciá-los nas orientações estratégicas e nas relações de troca de recursos com a subsidiária. Há necessidade de coordenar as operações no exterior para garantir que elas contribuam para uma estratégia integrada em todo o mundo, porém há necessidade também de as subsidiárias terem representatividade na gestão global, pois seria uma perda se todas as empresas subsidiárias colocassem suas posições como passivas. Estes, são ativos valiosos que precisam ser ligados em uma estratégia global, não enfraquecidas ou subjugadas ao controle centralizado (BARTLETT, 1992).

Bolino (2007) e Bolino e Feldman (2000) ressaltam que algumas subsidiárias darão contribuições mais importantes para a missão estratégica global da organização do que outras, além de que algumas subunidades estarem localizadas em países ou mercados que possuem maior representação nos negócios da empresa. Assim, os expatriados que tenham sido atribuídos às unidades de maior importância tenderão a se 
aproximar do núcleo da missão global da organização. Quando eles forem repatriados, deverão ser promovidos mais rapidamente do que aqueles que foram designados para unidades que tenham menor relevância estratégica para a matriz (BOLINO, 2007). Dessa maneira, Bolino (2007) ressalta a importância estratégica do papel da subsidiária, em termos de entradas e saídas de conhecimento, e a importância estratégica do mercado em que se situa a subsidiária.

Dentre os diferentes procedimentos, há um de maior repercussão. O feedback da repatriação não deve ser somente centrado no indivíduo, mas abranger toda a estratégia. Esse retorno do desempenho deve ser individual, afinal a empresa deve um retorno para o empregado, mas também deve haver um retorno organizacional. A falta desse retorno organizacional é um dos motivos que levam o processo de expatriação a ser visto como uma prática com início, meio e fim. E na verdade, ele é um ciclo. Considerando que a missão seja estratégica, o retorno da expatriação seria o feedback da estratégia, logo seria a base para as próximas estratégias da organização.

Os problemas da expatriação são relativos a uma área com papel limitado e, em alguns casos, inexistente, sendo sua atual função principalmente de apoio administrativo (HALCROW, 1999; KLAFF, 2002). Esse panorama também ocorre nas organizações nas quais alguns membros do setor de GRH são dedicados exclusivamente a questões internacionais. Essa lacuna mostra que a GRH ainda tem de se tornar um parceiro estratégico em todos os aspectos do negócio (HALCROW, 1999). Muito do trabalho que agora é feito, rotineiramente, na GHR em relação a assuntos domésticos ainda tem de ser aplicado a operações fora do país de origem.

O problema é que poucas organizações possuem uma visão nítida de sua estratégia empresarial global, a ponto de poder traduzi-la em necessidades específicas de desenvolvimento (MCCALL; HOLLENBECK, 2003). Isso ressalta a necessidade de planejamento da organização, bem como de entendimento de suas práticas para traçar objetivos e maximizar resultados.

A repatriação, assim como todo o processo de expatriação, pode ter foco no indivíduo (como fatores de adaptação e problemas familiares) e foco na empresa (contribuição dessa experiência para a empresa e quais os ganhos que se vai ter). Embora essas duas perspectivas estejam vinculadas e relacionadas, a literatura tem dado foco para o indivíduo, pois, se este não está bem adaptado, não terá condições de realizar seu trabalho. Entretanto, nas operações bem-sucedidas, o foco continua sendo o individual e pouco se tem estudado a contribuição organizacional que o expatriado traz. Muitas vezes, esse foco é negligenciado em função do pouco espaço que a organização dá para a expatriação. A área de GRH também possui significativo papel na sinalização de novos conhecimentos e competências obtidos.

Lazarova e Caligiuri (2004) analisam que, dada a importância estratégica de um processo de repatriamento bem-sucedido e suas implicações em escala global, as soluções para o problema de repatriamento devem, igualmente, ser estratégicas. As autoras relatam como primeiro fator a questão da carreira, isto é, a empresa deve perceber que as pessoas têm objetivos diferentes de carreira. $O$ segundo fator é a tendência de as multinacionais tratarem todas as tarefas globais como se tivessem o mesmo objetivo estratégico. Algumas repatriações têm objetivos funcionais, por isso, diferentes atribuições globais devem 
ter estratégias diferentes de repatriação. 0 terceiro fato é as multinacionais, muitas vezes, não conseguirem integrar sistemas de seleção, gestão de desempenho e repatriação em um processo estratégico, quando necessário (LAZAROVA; CALIGIURI, 2004).

Após essa breve elucidação sobre a expatriação vislumbra-se a necessidade de realizar pesquisas nesse campo. É importante, entretanto, que esse tema seja analisado de maneira global, estratégica e organizacional, retirando o foco do indivíduo. Além disso, analisar tal assunto como um processo é outro fator de destaque: a expatriação não acaba na repatriação, mas é o início de novas estratégias.

Além dos diversos níveis de internacionalização apresentados e das orientações de gestão, existe o processo de expatriação. Compreender as diversas etapas, políticas e práticas da expatriação; como a orientação de gestão acaba refletindo na quantidade de expatriações que estão ocorrendo ou que devem ocorrer; e analisar o feedback das expatriações como apoio para entender o panorama de internacionalização da empresa, são algumas questões oportunas para analisar dentro da estratégia de internacionalização. Esses assuntos estão, portanto, relacionados e acabam afetando um ao outro, sendo oportuno entendê-los sob a mesma perspectiva. A possibilidade de criar um modelo que contemple esses aspectos pode levar à melhor compreensão da importância da expatriação, bem como dos rumos da internacionalização da empresa.

\section{CONSIDERAÇÕES FINAIS}

A função organizacional da Gestão de Recursos Humanos vem obtendo destaque e mostrando sua importância dentro das empresas. Os gerentes de linha envolvem-se na GRH e gestores de Recursos Humanos tornam-se membros da equipe de gestão. Além disso, como a Gestão de Recursos Humanos é considerada fundamental para o desenvolvimento da empresa, praticamente todos os envolvidos podem, simultaneamente, dar sua contribuição para a GRH e para o sucesso da empresa.

Em comparação com o 'passado, hoje e amanhã', as caracterizações da GRH refletem-se nos contextos regional, nacional e na competição global. Essas alterações são: projeção da força de trabalho; alterações legais e regulamentares; significativos desenvolvimentos tecnológicos (SCHULER, 2000). Traduzidas em grandes mudanças na estratégia organizacional, essas forças requerem velocidade, qualidade, inovação e globalização das empresas que desejam sobreviver no campo da concorrência internacional (SCHULER, 2000). Disso origina-se a necessidade tanto de utilizar o conhecimento da área de GRH, como de compreendê-la de maneira mais estratégica.

A GRH busca a rápida valorização e o desenvolvimento de todos os aspectos das atividades nacionais, internacionais e globais, além de melhor entendimento dos problemas associados a essa área e por ela afetados. Devido à grande importância de uma Gestão de Recursos Humanos eficaz no contexto mundial, muitas empresas estão dedicando mais tempo, atenção, habilidade e esforço em fazê-la bem (SCHULER, 2000).

Dentro das estratégias internacionais da empresa, existem processos que auxiliam na condução dos negócios globais. A expatriação é um deles, em função da amplitude e da riqueza de conhecimento que 
envolvem esse processo. Por isso, o presente ensaio buscou mostrar que a expatriação é um processo que oferece suporte para a estratégia de internacionalização organizacional.

Quando a expatriação está desconexa das estratégias organizacionais, as falhas do processo ficam mais evidentes. Exemplo disso é a dificuldade de se repatriar com sucesso. Como a expatriação não é visualizada como um processo mais amplo, o foco da organização acaba sendo a segunda fase da expatriação (foco na subsidiária), em função do objetivo imediato (desenvolvimento de líder, expansão de mercado, entre outros). Logo, quando os repatriados voltam para o país de origem, ficam desmotivados, porque sua volta não fazia parte das estratégias da organização. Para que se tenha uma GRHI, é necessário entender a repatriação, bem como as outras fases da expatriação, mais do que como parte significativa do processo de internacionalização, ou seja, é oportuno reconhecê-la como parte das estratégias da empresa.

Outro fator relacionado à repatriação é que as pesquisas têm focado o desempenho individual da repatriação (ascensão do empregado após a repatriação, por exemplo), entretanto o desempenho deve ser analisado organizacionalmente, para que a empresa possa entender tanto o direcionamento de sua internacionalização como o desenvolvimento de suas subsidiárias.

Esse exemplo mostra como é relevante que a empresa veja a expatriação de forma ampla e entenda como cada fase impacta em sua estratégia. Entender quais práticas estão interligadas com esse processo é igualmente necessário, para que se possa compreender os impactos, as implicações e os resultados da expatriação como um processo de gestão. Aqui surge outro problema desta temática: o entendimento da expatriação como um processo com começo, meio e fim. Além de considerar sua importância estratégica, é necessário entender a repatriação dentro de um amplo processo, caso contrário ela transforma-se no final de uma prática e não em início de novos conhecimentos para a matriz.

A expatriação acaba envolvendo também outros fatores. Os estudos sobre internacionalização da GRH destacam as decisões tomadas na matriz que são exportadas diretamente para as subsidiárias. Em busca de maior autonomia para as subsidiárias, o contexto local ao invés da influência da matriz tem sido foco das pesquisas. De fato, os estudos não têm conseguido conciliar as políticas e as práticas da matriz e da subsidiária, como mostra o exemplo de insucesso da repatriação. Um dos desafios da área é auxiliar nessa interface, alinhando os processos internos das subsidiárias, para que eles possam apoiar e não se tornar um empecilho à colaboração externa (TANURE et al., 2007).

É importante também entender como as práticas de GRH estão mutuamente relacionadas, tornandose base para auxiliar no processo de expatriação, a fim de torná-la estratégica no contexto internacional. Igualmente, mostrar que essa área possui papel estratégico na organização e que, com a implementação de políticas e práticas articuladas ao plano estratégico, ela se torna indispensável para o desenvolvimento global da empresa.

Enfim, a contribuição deste ensaio teórico refere-se à necessidade de construção de um modelo para compreender e demonstrar as fases e os procedimentos da GRH envolvidos no processo de expatriação. Não há, na literatura de GRH Internacional, um modelo que contemple as fases, políticas e práticas pertinentes a esses processos, além de não existir um consenso sobre quais fases e práticas são pertinentes a esse 
processo. Assim, existem, pois, diversos conceitos, configurações e modelos de expatriação, cada um com sua importância dentro da temática, tal como foi demonstrado. Ademais, as diversas configurações de expatriados apontam para o uso de diferentes estratégias organizacionais e os conceitos ressaltam a divergência do entendimento sobre a expatriação.

A justificativa da construção do modelo teórico é falta do entendimento e da visualização desse processo, o que pode impactar na consecução da estratégica organizacional. Quando o processo não está claro, as estratégias também ficam comprometidas. Isso pode estar vinculado aos fatores de insucessos da expatriação, pois esse processo é estruturado perante uma estratégia organizacional.

\section{REFERÊNCIAS}

ANDO, N.. Isomorphism and foreign subsidiary staffing policies. Cross Cultural Management: An International Journal, v.18, n.2, p.131-141, 2011.

BARTLETT, C.. Christopher Bartlett on Transnationals: An Interview. European Management Journal, v.10, n.3, 1992.

BECKER-RITTERSPACH, F.; DÖRRENBÄCHER, C.. An Organizational Politics Perspective on Intra-firm Competition in Multinational Corporations. Manag Int Ver, v.51, p.533559, 2011.

BIANCHI, E. M. P. G.. Gestão e carreira internacional: repatriação: construindo elos entre ciclos. In: ENCONTRO NACIONAL DOS PROGRAMAS DE PÓS-GRADUAÇÃO EM ADMINISTRAÇÃO, 35. Anais. Rio de Janeiro, 2011.

BLACK, J. S.; GREGERSEN, H. B.. The Right Way to Manage Expats. Harvard Business Review, p.52-62, 1999.

BLACK, J. S; GREGERSEN, H. B; MENDENHALL, M.. Toward a theoretical framework of repatriation adjustment. Journal of International Business Studies, v.23, n.4, p.373-760, 1992

BOHLANDER, G.; SNELL, S.; SHERMAN, A.. Administração de Recursos Humanos. São Paulo: Pioneira Thomson Learning, 2003.

BOLINO, M. C.. Expatriate assignments and intraorganizational career success: implications for individuals and organizations. Journal of International Business Studies, v.38, p.819-835, 2007.

BOLINO, M. C.; FELDMAN, D. C.. The antecedents and consequences of underemployment among expatriates. Journal of Organizational Behavior, v.21, n.8, p.889-911, 2000.

BOXALL, P.; PURCELL, J.. Strategy and Human Resource Management. New York: Palgrave Macmillan, 2008.

CALIGIURI, P. M.. Selecting expatriates for personality characteristics: a moderating effect of personality on the relationship between host national contact and crosscultural adjustment. Management International Review, v.40, n.1, p.61-80, 2000
CAPES. Coordenação de Aperfeiçoamento de Pessoa de Ensino Superior, 2012.

DE CIERI, H.; DOWLING, P. J.; TAYLOR, K. F.. The psychological impact of expatriate relocation on partners. The International Journal of Human Resource Management, v.2, n.3, p.377-414, 1991.

DE RÉ, C. A.; DE RÉ, M. A.. Processos do Sistema de Gestão de Pessoas. In: BITENCOURT, C.. Gestão Contemporânea de Pessoas. Porto Alegre: Bookman, 2011.

DERESKY, H.. Administração global: estratégica e interpessoal. Porto Alegre: Bookman, 2004.

DÖRRENBÄCHER, C.; GEPPERT, M.. Subsidiary staffing and initiative-taking in multinational corporations: A sociopolitical perspective. Personnel Review, v.39, n.5, p.600621, 2009.

DUTRA, J. S.. Gestão de pessoas. Modelo, Processos, Tendências e Perspectivas. São Paulo: Atlas, 2002.

FREITAS, M. E.; DANTAS, M.. O Estrangeiro e o novo grupo. Revista de Administração de Empresas (RAE), v.51, n.6, p.601-608, 2011.

HALCROW, A.. Expats: the squandered resource. Workforce, v.87; n.4.; p.42, 1999

HARVEY, M.; NOVICEVIC, M.. The evolution from repatriation of managers in MNEs to "patriation" in global organizations In: STAHL, G. K.; BJÖRKMAN, I.. Handbook of Research in International Human Resource Management. Massachusetts: Edward Elgar, 2006.

HARVEY, M.; RALSTON, D; NAPIER, N.. International relocation of inpatriate managers: assessing and facilitating acceptance in the headquarters organization. International Journal of Intercultural Relations, v.24, p.825-846, 2000.

HOMEM, I. D.; DELLAGNELO, E. H. L.. Novas formas organizacionais e os desafios para os expatriados. Revista de Administração de Empresas (RAE), v.5, n.1, 2006.

IVANCEVICH, J. M.. Gestão de recursos humanos. 10 ed. São Paulo: McGraw-Hill, 2008. 
KLAFF, L.. The right way to bring expats home. Workforce, v.81, n.7, p.40, 2002.

LAZAROVA, M.; CALIGIURI, P.. Repatriation and Knowledge Management. In: HARZING; A.; RUYSSEVELDT, J. V. International human resource management. London: SAGE Publications, 2004.

LIMA, M. B.; BRAGA, B. M.. Práticas de recursos humanos do processo de repatriação de executivos brasileiros. Revista de Administração Contemporânea (RAC), v.14, n.6, p.10311053, 2010.

MCCALL, M. JR.; HOLLENBECK, G. P.. Desenvolvimento de executivos globais. As lições da experiência internacional. Porto Alegre: Bookman, 2003.

MENDENHALL, M. E.; DUNBAR, E. E.; ODDOU, G.. Expatriate selection, training and career-pathing: a review and a critique. Human Resource Planning, v.26, n.3, p.331-345, 1987.

MENDENHALL, M. E.; JENSEN, R. J.; BLACK, J. S.; GREGERSEN, $H$. B.. Human resource management challenges in the age of globalization. Organizational Dynamics, v.32, n.3, p.261-274, 2003.

MURITIBA, P. M.; ALBUQUERQUE, L. G.. Características da gestão estratégica de pessoas para as organizações internacionalizadas. In: ALBUQUERQUE, L. G.; LEITE, N. P.. Gestão de pessoas: perspectivas estratégicas. São Paulo: Editora Atlas, 2009.

NOGUEIRA, A. J. F. M.; BARRETO, S.; DELGADO, M. P.. Gestão de recursos humanos no processo de internacionalização. In: SEMINÁRIOS EM ADMINISTRAÇÃO, 12. Anais. São Paulo, 2009.

NUNES, L. H.; VASCONCELOS, I. F. G.; JAUSSAUD, J.. Expatriação de Executivos. São Paulo: Thomsom Learning, 2008.

BRASIL. Lei n.7.064, de 06 de dezembro de 1982. Brasília: DOU, 1982.

BRASIL. Lei n.11.962, de 06 de julho de 2009. Brasília: DOU, 2009.

QUINTANILLA, J.. Dirección de recursos humanos em empresas multinacionales: las subsidiarias al descubierto. Madrid: Prentice Hall, 2002.

QUINTANILLA, J.; SUSAETA, L. SANCHEZ-MANGAS, R.. The diffusion of employment practices in multinationals: 'americanness' within US MNCs in Spain?. Journal of Industrial Relations, v.50, n.5, p.680-696, 2008.
REGO, A.; CUNHA, M. P. E.. Manual de gestão transcultural de recursos humanos. Lisboa: $\mathrm{RH}, 2009$.

RICHEY, B.; WALLY, S.. Strategic human resource strategies for transnationals in Europe. Human Resource Management, v.8, n.1, p.79-97, 1998.

SCHULER, R. S.. The internationalization of human resource management. Journal of International Management, v.6, p.239-260, 2000

SCHULER, R. S.; BUDHWAR, P. S.; FLORKOWISKI, G. W.. International human resource management: review and critique. International Journal of Management Reviews, v.4, n.1, p.41-70, 2002

SCHULER, R. S.; DOWLING, P. J.; DE CIERI, H.. An integrative framework of strategic international human resource management. Journal of Management, v.19, n.2, p.419-459, 1993.

SHEPHARD, P.. Working with malaysians: expatriates' and malaysians perspectives. In: ABDULLAH, A.. Understanding the Malaysian workforce: Guidelines for managers. p. 144 155, 1996.

STROH, L. K.. Predicting turnover among repatriates: can organizations affect retention rates?. The International Journal of Human Resource Management, v.6, n.2, 1995.

TANURE, B.; EVANS, P.; PUCIK, V.. A Gestão de Pessoas no Brasil. Virtudes e Pecados Capitais. Estudos de Caso. Rio de Janeiro: ELSEVIER, 2007.

TUNG, R. L.. Career issues in international assignments. the academy of management executive. v.11, n.3, p.241-244, 1988.

TUNG, R. L.. Expatriates assignments: enhancing success and minimizing failure. The Academy of Management Executive, v.1, p.117-126, 1987.

TUNG, R. L.. American expatriates abroad: from neophytes to cosmopolitans. Journal of World Business, v.33, n.2, p.125-144, 1998.

ULRICH, D.. Introdução. In: ULRICH, D.. Recursos humanos estratégicos: novas perspectivas para os profissionais de $\mathrm{RH}$. São Paulo: Futura, 2000.

VANCE, C. M.; PAIK, Y.. Managing a global workforce: challenges and opportunities in international human resource management. New York: M. E. Sharpe, 2006.

ZWIELEWSKI, G.. Desafios da Expatriação. 2009. 